\title{
Study of the relationship between fractures and highly productive shale gas zones, Longmaxi Formation, Jiaoshiba area in eastern Sichuan
}

\author{
Yu-Feng $\mathrm{Li}^{1,2} \cdot$ Wei Sun ${ }^{2} \cdot \mathrm{Xi}-\mathrm{Wu} \mathrm{Liu}{ }^{2} \cdot$ Dian-Wei Zhang ${ }^{2} \cdot$ Yan-Chun Wang $^{1} \cdot$ Zhi-Yuan Liu $^{2}$
}

Received: 16 October 2017 / Published online: 6 August 2018

(c) The Author(s) 2018

\begin{abstract}
Shale fractures are an important factor controlling shale gas enrichment and high-productivity zones in the Longmaxi Formation, Jiaoshiba area in eastern Sichuan. Drilling results have, however, shown that the shale fracture density does not have a straightforward correlation with shale gas productivity. Based on logging data, drilling and seismic data, the relationship between shale fracture and shale gas accumulation is investigated by integrating the results of experiments and geophysical methods. The following conclusions have been drawn: (1) Tracer diffusion tests indicate that zones of fracture act as favorable channels for shale gas migration and high-angle fractures promote gas accumulation. (2) Based on the result of azimuthal anisotropy prediction, a fracture system with anisotropy strength values between 1 and 1.15 represents a moderate development of high-angle fractures, which is considered to be favorable for shale gas accumulation and high productivity, while fracture systems with anisotropy strength values larger than 1.15 indicate over-development of shale fracture, which may result in the destruction of the shale reservoir preservation conditions.
\end{abstract}

Keywords Azimuthal anisotropy $\cdot$ Fracture prediction $\cdot$ Shale $\cdot$ Shale gas $\cdot$ Shale reservoir preservation conditions

\section{Introduction}

According to the 2013 statistics from the United States Energy Information Administration, the global technically available resource of shale gas is up to $2.07 \times 10^{14} \mathrm{~m}^{3}$ (EIA 2013). China is rich in shale gas too. The shale resources in China are mainly located in the Sichuan, Ordos, Bohai Bay, Songliao, Tarim and Junggar Basins, with an estimated volume in place between $1.5 \times 10^{13}$ and $3.0 \times 10^{13} \mathrm{~m}^{3}$ (Zhang et al. 2008; Jia 2017; Jiang et al. 2015; Wang et al. 2016). Shale gas fields of the Sichuan Basin are mostly located in the Fuling area in eastern Sichuan; and the Weiyuan, Changning, Zhaotong and Fushun-Yongchuan areas in southern Sichuan. Among these, the shale gas fields

Edited by Jie Hao

Yu-Feng Li

lyfsw1984@163.com; 794061661@qq.com

1 School of Geophysics and Information Technology, China University of Geoscience, Beijing 100083, China

2 Research Institute of Petroleum Exploration and Development, Sinopec, Beijing 100083, China of the Jiaoshiba area in Fuling contribute an annual production of $5.0 \times 10^{9} \mathrm{~m}^{3}$ (Guo 2016a, b; Wang 2017).

Both the reservoir space and accumulation mechanisms of shale gas are complex (Liang et al. 2012; Gale et al. 2014; Deng et al. 2015; Tenger et al. 2017), and it is difficult to ascertain the key factor controlling shale gas accumulation (Guo and Zhang 2014; Jin et al. 2016; Guo et al. 2017). This comprehensive study considers that shale fractures are a key factor controlling shale gas accumulation and productivity. For conventional oil and gas, shale fractures serve as both oil and gas accumulation space and migration channels for hydrocarbons. However, drilling results have shown that natural shale fractures are not always positively correlated with high productivity. Particularly in fracture over-developed reservoirs, the shale gas production rates seem to be inadequate. Therefore, it is imperative to determine how to establish the relationship between fracture development and the production by available geological and geophysical methods.

In this study, we integrated the well log, drilling and seismic data from the Longmaxi Formation in the Jiaoshiba area of the eastern Sichuan Basin, performing tracer analysis on core samples and undertaking pre-stack seismic 
fracture predictions (Yin et al. 2012; Kong et al. 2012; Zhang et al. 2013; Sun et al. 2013a, b, 2014a, b; Chen et al. 2014a, b, 2015). The results reveal the complicated relationship between fracture development and gas production from the shale reservoirs.

\section{Shale fracture formation mechanism}

The shale gas production layer in the Jiaoshiba area is a set of high-quality shales in the Silurian Longmaxi Formation and Ordovician Wufeng Formation (the two formations have the same lithology and the thickness of the Wufeng Formation is less than $10 \mathrm{~m}$, which cannot be distinguished with seismic data) (Guo 2015). As shown in Fig. 1, the main structure of the study area is characterized by the northeast direction of the box-shaped anticline, with a feature of wide south, narrow north and light central. Multiple reverse faults developed on both sides of anticline.
Reverse faults are widely developed in shale within the research area where most of the tectonic stress is compressional. It is generally recognized that shale deposition is cyclic, resulting in strong heterogeneity and the development of planes of weakness along bedding or bed-parallel (Zeng and Xiao 1999; Zhou et al. 2015). According to outcrop and core samples, shale fractures in the Jiaoshiba area are categorized as bed-parallel fractures and bed-cutting, high-angle fractures, as shown in Fig. 2. In addition, previous studies based on a large number of core observations and imaging logging data (Guo and Liu 2013; Guo 2016a, b) suggest that: (1) seen from the core, the fractures whether bed-parallel or bed-cutting are mostly calcite-filled or semi-filled, as shown in Fig. 3; (2) in a vertical view, the fractures are more developed in the lower part of the Silurian Longmaxi Formation and the Ordovician Wufeng Formation, and the fractures are mostly developed in the Wufeng Formation.

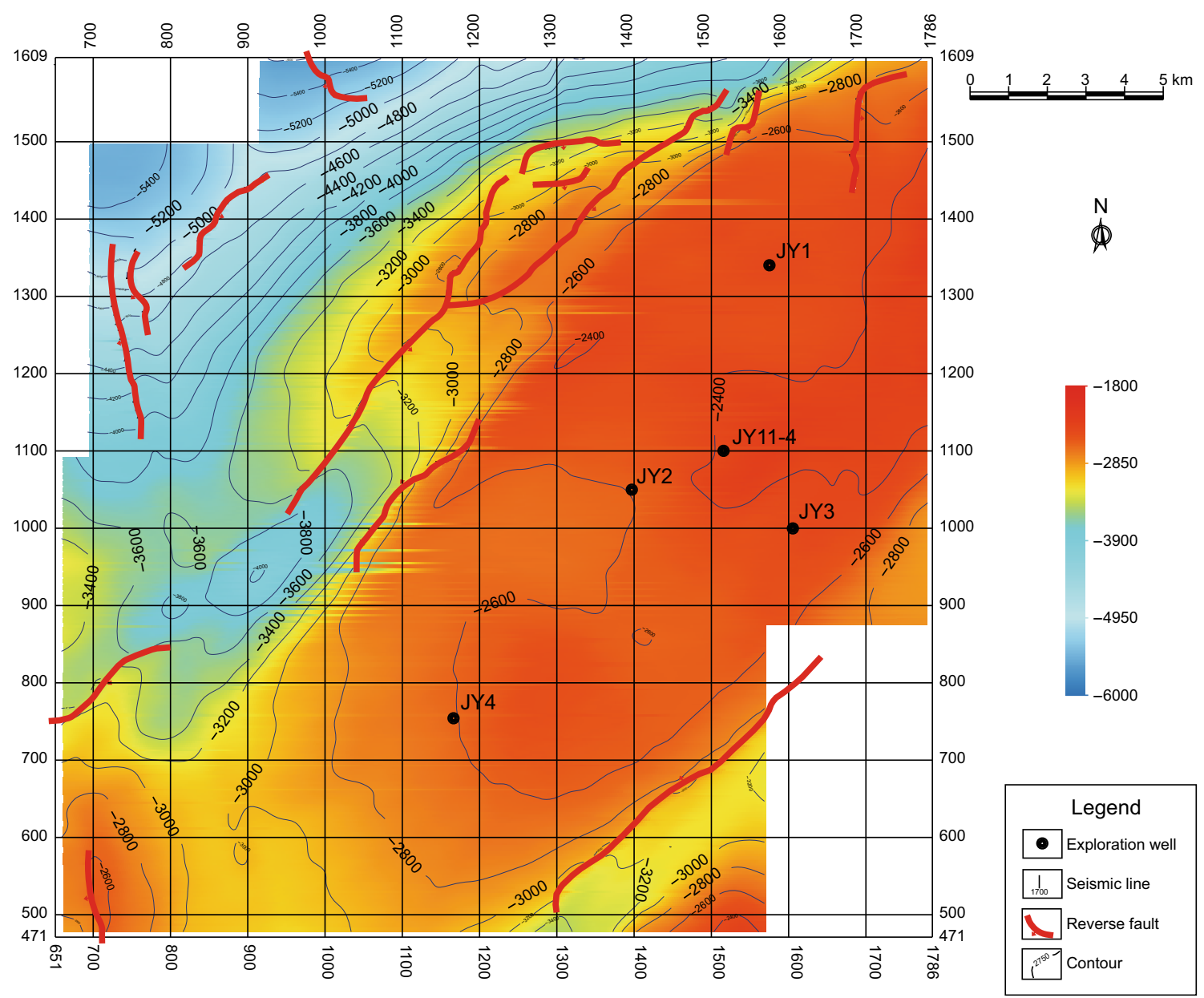

Fig. 1 Structural map of the bottom interface of the Silurian Longmaxi Formation and Ordovician Wufeng Formation in the study area 


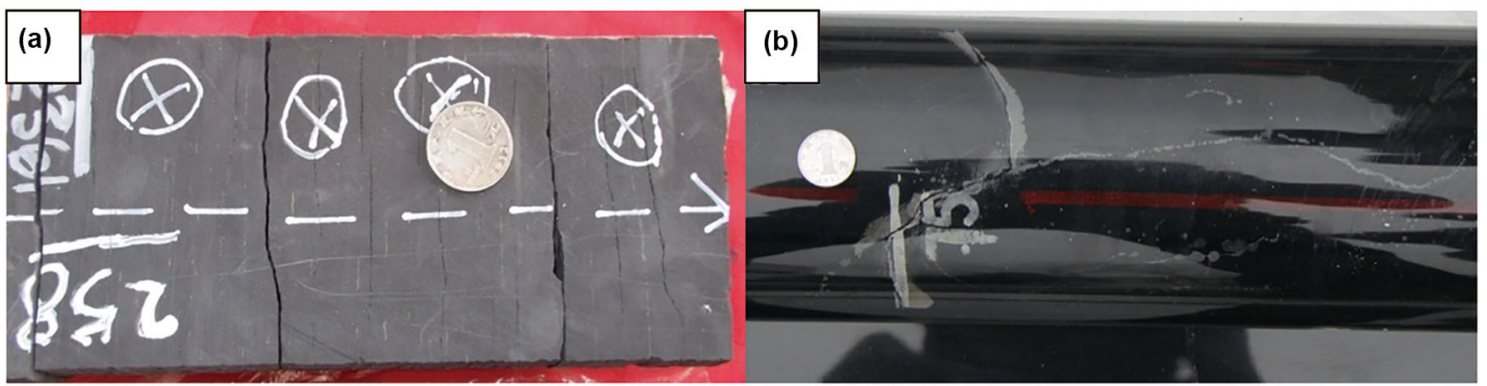

Fig. 2 Core photographs of fractures in well Jiaoye 11-4 and Jiaoye 41-5 in the study area. a Jiaoye 11-4 Well Longmaxi Formation bed-parallel fracture, b Jiaoye 41-5 well Longmaxi Formation high-angle bed-cutting fracture

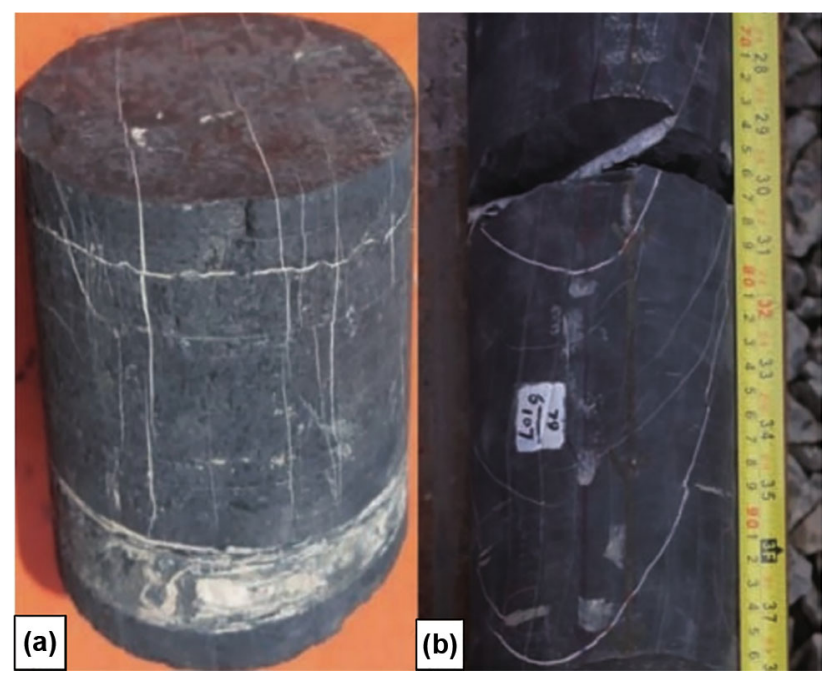

Fig. 3 Core photographs of fractures in well Jiaoye 1 in the study area. a Calcite-filled bed-parallel and bed-cutting fractures in the Ordovician Wufeng Formation, b calcite-filled bed-cutting fractures in the lower part of the Silurian Longmaxi Formation

(a)

Diffusion distance from the bottom up, $\mu \mathrm{m}$

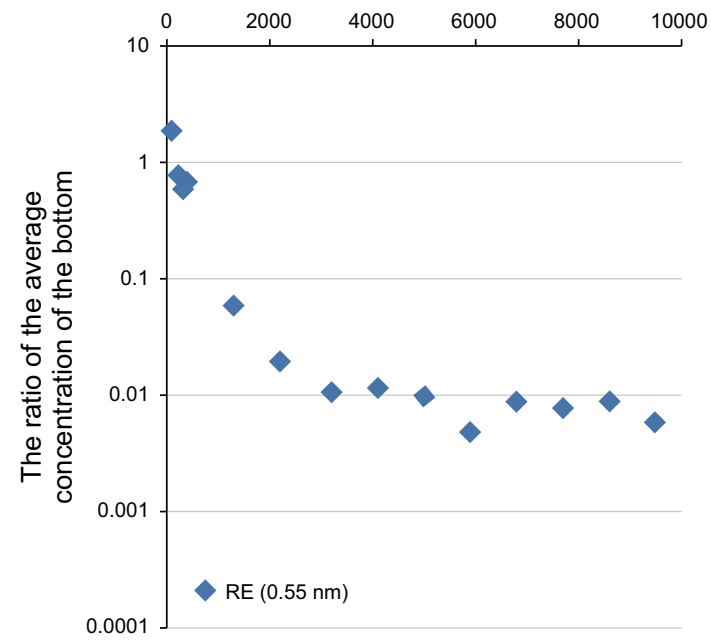

\section{Influence of shale fractures on shale gas accumulation}

Shale reservoir pore structure is complicated and mainly micro- or nanoscale. In this study, a tracer diffusion experiment is used to evaluate pore connectivity, which determines the impact of fracture on shale gas migration (Yang et al. 2017a, b). The diffusion experiment workflow is listed as follows:

1. Place dried shale samples for $12-24 \mathrm{~h}$ in a $99.992 \%$ vacuum; the samples are then immersed in brine without tracers and fully saturated.

2. Place the brine saturated shale sample on top of a porous ceramic plate in the tracer tank, where only the base of the shale sample is in direct contact with the tracer solution to allow the tracer to diffuse freely from the base to all parts of the shale sample.

3. $25 \mathrm{~h}$ later, the shale samples are taken out of the solution tank, quickly frozen using liquid nitrogen and only handled following freeze-drying. Finally, LA-

(b)

Diffusion distance from the bottom up, $\mu \mathrm{m}$

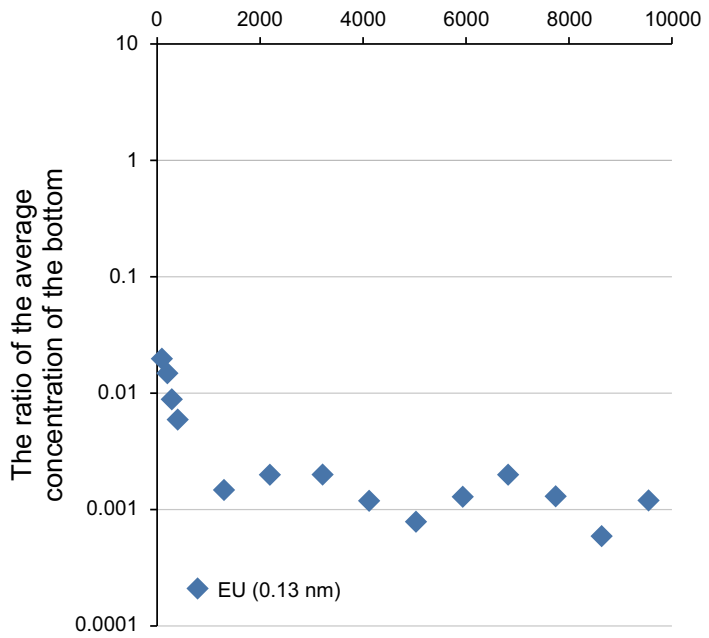

Fig. 4 Tracer diffusion results of $\mathrm{ReO}_{4}^{-}$rhenium complex (a) and europium complex (b) 
ICP-MS is used to analyze how the tracer diffuses in the saturated shale samples.

It is generally believed that the molecular diameter of methane gas is $0.38 \mathrm{~nm}$ (Wu and Zhang 2016). The tracer used in this experiment includes anionic $\mathrm{ReO}_{4}^{-}$rhenium complex $\left(0.55 \mathrm{~nm}\right.$ diameter) and cationic $\mathrm{Eu}^{3+}$ europium complex $(0.13 \mathrm{~nm}$ diameter). The tracer diffusion results and diffusion distances are analyzed jointly as shown in Fig. 4. It can be seen that as diffusion distance increases, the ratio of $\mathrm{ReO}_{4}^{-}$rhenium oxide complex concentrations between the upper part and the lower part of the shale sample is 0.01 (that is, $1 \%$ of the pores connect); however, for the europium complex the value is maintained at 0.001 (that is, $0.1 \%$ of the pores connect). Considering that the molecular diameter of the main component of shale gasmethane lies between the diameters of the two tracers, it is believed that the percentage of connected pores in the shale formations of this area will be less than $1 \%$. Therefore, fractures and particularly high-angle fractures are the main channel allowing for effective migration of shale gas.

\subsection{Technical principle}

The VTI (transverse isotropy with a vertical axis of symmetry) and HTI (transverse isotropy with a horizontal axis

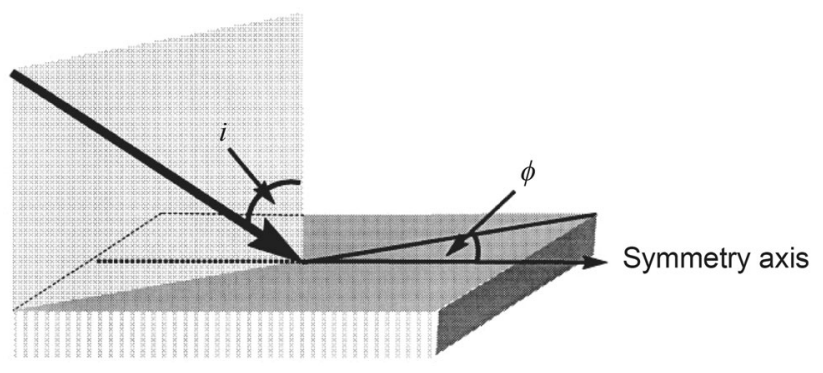

Fig. 5 Diagram of P-wave incidence in an HTI model [Cited from Ruger (1997a, b), revised] of symmetry) models are the two most extensively used matrix models in fracture studies. The HTI medium model is normally used for high-angle fracture studies. The VTI model is more representative of horizontal fracture scenarios.

In shale reservoirs, the bedding structure of shale is similar to a VTI matrix, and bed-parallel fractures in shale layers commonly developed along weak bedding planes. Such minor bedding fracture only gives rise to small variance in seismic amplitude, which can easily be overwhelmed by the impact of lithology changes. In the case of high-angle fracture, a network of fractures is developed both horizontally and vertically, which is beneficial to shale gas migration. And the prediction method for highangle fracture based on an HTI matrix is more mature (Sun et al. 2013a, b, 2014a, b). For this reason, this paper focused on the prediction of high-angle fractures.

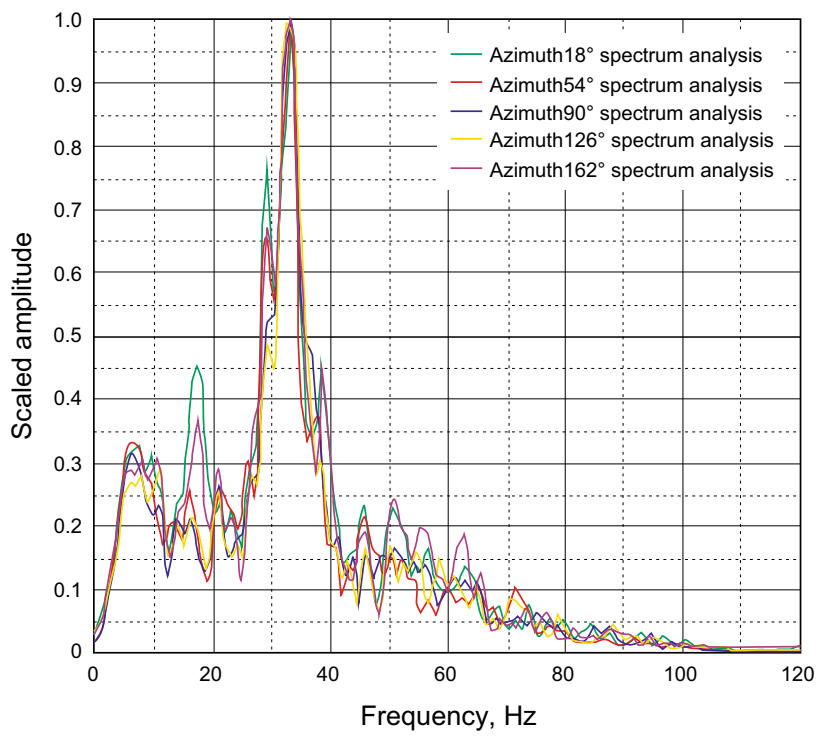

Fig. 7 Frequency spectrum of each azimuthal migrated data cube

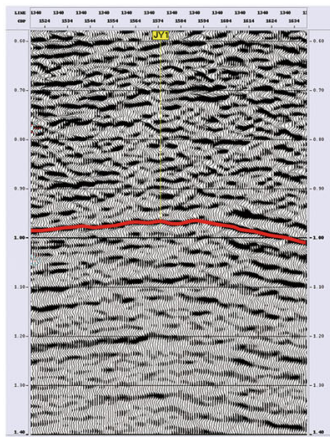

(a) Azimuth $18^{\circ}$ data

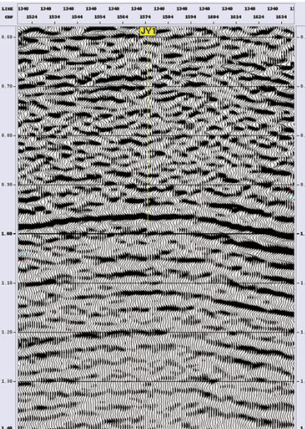

(b) Azimuth $54^{\circ}$ data

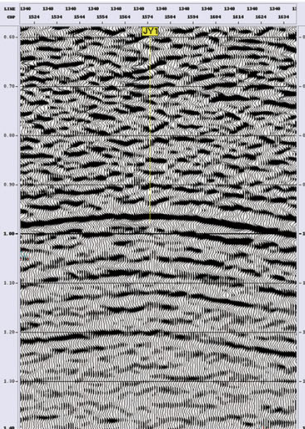

(c) Azimuth $90^{\circ}$ data

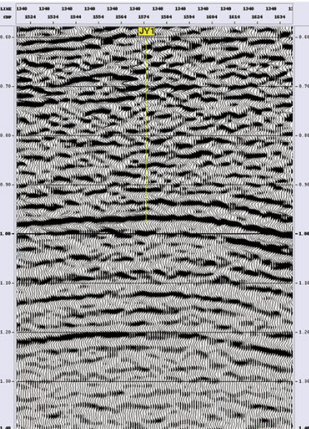

(d) Azimuth $126^{\circ}$ data

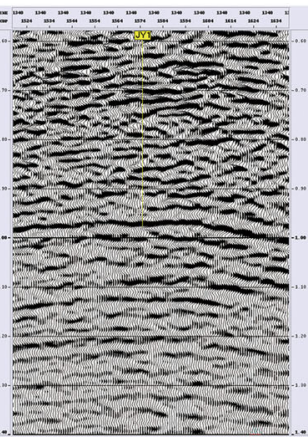

(e) Azimuth $162^{\circ}$ data

Fig. 6 Section of five migrated azimuth seismic data. a azimuth $18^{\circ}$ data, $\mathbf{b}$ azimuth $54^{\circ}$ data, $\mathbf{c}$ azimuth $90^{\circ}$ data, $\mathbf{d}$ azimuth $126^{\circ}$ data, e azimuth $162^{\circ}$ data 


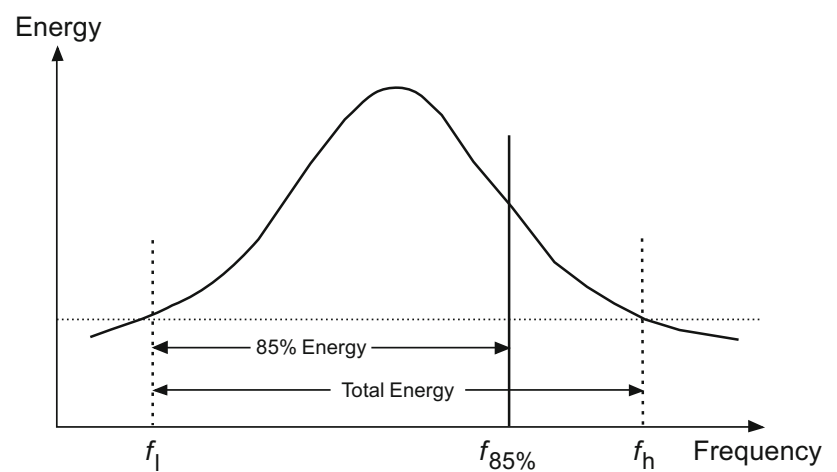

Fig. 8 Sketch map of the $85 \%$ attenuation frequency attribute

For seismic fracture prediction in HTI media, the most widely used approach involves the Ruger formula (1997a, b), as shown in Eq. (1):

$$
\begin{aligned}
R_{\mathrm{P}}(\theta, \varphi)= & \frac{\Delta Z}{2 \bar{Z}}+\frac{1}{2}\left\{\frac{\Delta \alpha}{\bar{\alpha}}-\left[\frac{2 \bar{\beta}}{\bar{\alpha}}\right]^{2} \frac{\Delta G}{G}\right] \\
& \left.+\left[\Delta \delta+2\left(\frac{2 \bar{\beta}}{\bar{\alpha}}\right)^{2} \Delta \gamma\right] \cos ^{2} \varphi\right\} \sin ^{2} \theta \\
& +\frac{1}{2}\left\{\frac{\Delta \alpha}{\bar{\alpha}}+\Delta \varepsilon \cos ^{4} \varphi+\Delta \delta \sin ^{2} \varphi \cos ^{2} \varphi\right\} \sin ^{2} \theta \tan ^{2} \theta
\end{aligned}
$$
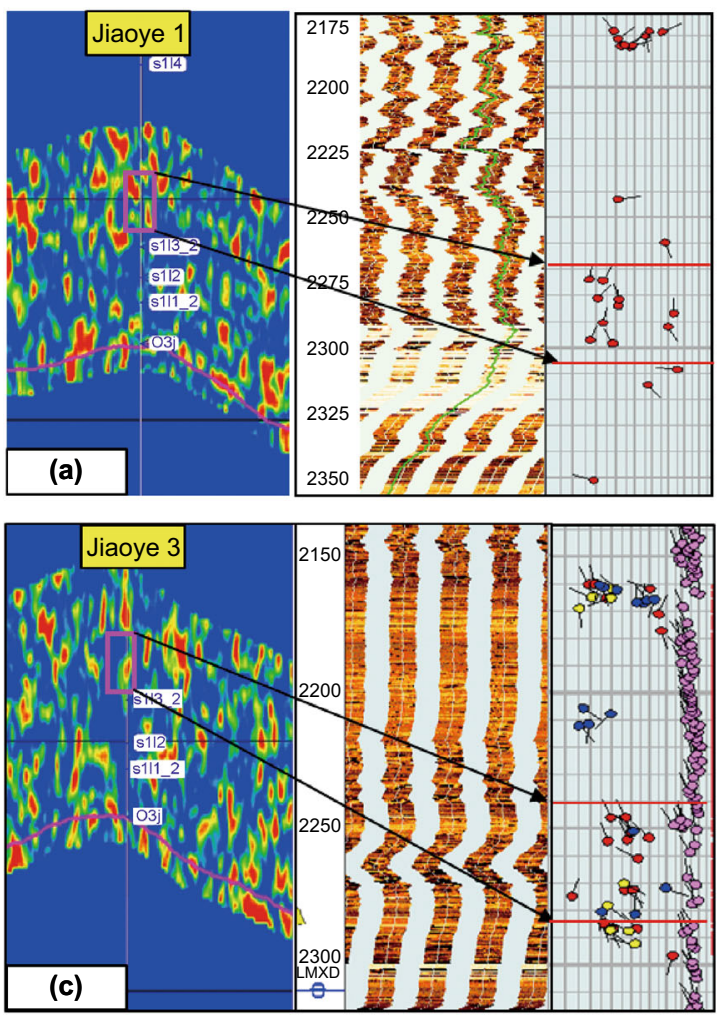

Fig. 9 Comparison of predicted anisotropy strength with single-well image logging. a Jiaoye 1 well comparison of predicted fracture versus image logging, b Jiaoye 2 well comparison of predicted
In this equation, $\theta$ is incident angle and $\varphi$ is azimuth angle (see Fig. 5). $R_{\mathrm{P}}(\theta, \varphi)$ is $\mathrm{P}$-wave reflection coefficient; $Z=\rho \times \alpha$, where $Z$ is P-wave impedance in $\mathrm{g} / \mathrm{cm}^{3} \mathrm{~m} / \mathrm{s}, \rho$ is density in $\mathrm{g} / \mathrm{cm}^{3}$, while $\alpha$ is P-wave velocity in $\mathrm{m} / \mathrm{s}$; $\Delta Z / \bar{Z}$ is the ratio of the underlying layer' s impedance and the average impedance; $G=\rho \times \beta^{2}, G$ is S-wave modulus ( $\beta$ is S-wave velocity in $\mathrm{m} / \mathrm{s}$ ); $\gamma, \delta$ and $\varepsilon$ are Thomsen anisotropic parameters; $\Delta[\bullet]$ indicates the physical parameter difference between the upper interface and the lower interface; $\overline{[\bullet]}$ denotes the average value of the physical parameters of the upper and lower interfaces.

With smaller incident angles, Eq. (1) can be simplified by adding the isotropic term $B^{\text {iso }}$ and the anisotropic term $B^{\text {ani }}$. Seismic reflectance $R\left(\phi_{k}\right)$ is transformed into a function of $B^{\text {ani }}, B^{\text {iso }}$ and fracture azimuth $\phi_{\text {sym }}$ (Ruger 1997a, b), as shown in Eq. (2):

$R\left(\phi_{k}\right)=B^{\text {iso }}+B^{\text {ani }} \cos ^{2}\left(\phi_{k}-\phi_{\text {sym }}\right)$

where $\phi_{k}$ is the $k$ th observed azimuth and $\phi_{\text {sym }}$ is an azimuth parallel to the symmetry axis of the fracture zones. In the case where more than three acquisition azimuths have been acquired, with three unknowns, the equation can be solved as an overdetermined problem (Mallick et al. 1998). The isotropic and anisotropic terms are used to fit the
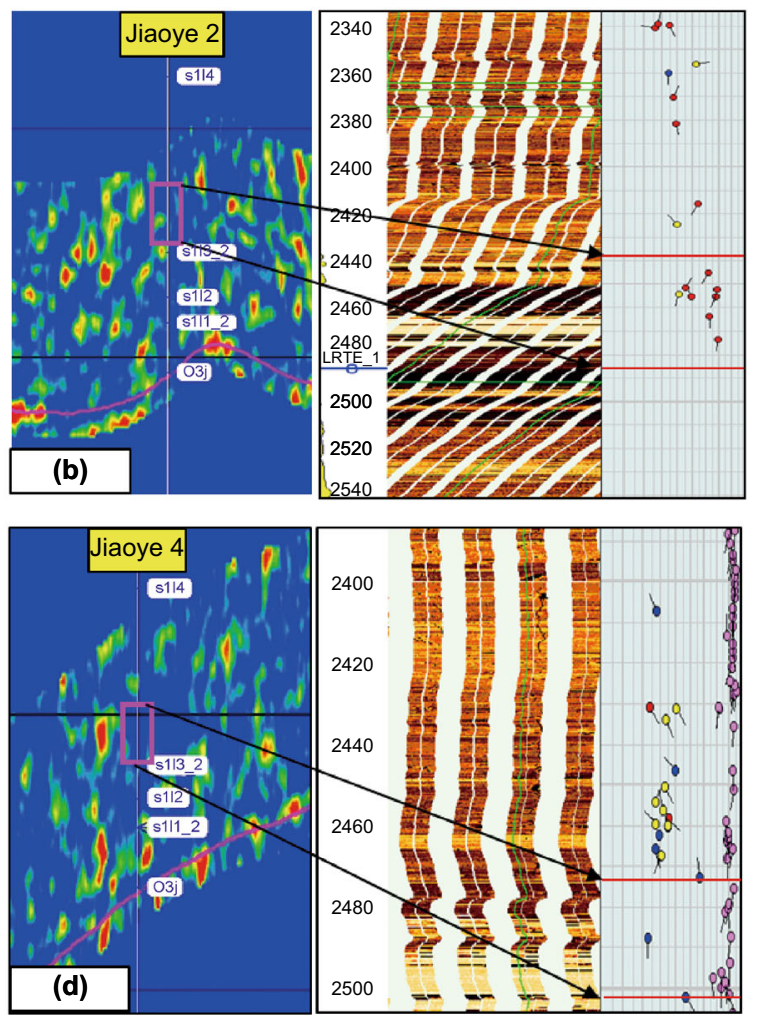

fracture versus image logging, c Jiaoye 3 well comparison of predicted fracture versus image logging, d Jiaoye 4 well comparison of predicted fracture versus image logging 
anisotropic ellipse, and the anisotropy strength can be indicated with the ratio of long axis to the short axis of the ellipse, while the direction of fracture can be indicated with the long axis or short axis direction. Furthermore, the greater development of the fracture, the stronger the anisotropy and the greater the oblateness of the ellipse is (Mallick et al. 1998; Sun et al. 2013a, b, 2014a, b). So, both strength and direction of fractures can be predicted.

\subsection{Data processing}

In this study, azimuthal and pre-stack Normal MoveOut (NMO) gathers which have undergone dynamic correction are the input data used to predict the azimuth anisotropy of the fractures. The detailed data processing steps are described below:
1. NMO gather analysis: NMO gather analysis is conducted in the Jiaoshiba area to determine the degree of coverage, azimuth and offset ranges of the seismic gathers.

2. Azimuthal stack and migration (Hao and Zhao 2004; Fan and $\mathrm{Mu}$ 2002). Based on the principle of energy balance, pre-stack seismic gather data are divided into five bins by azimuth angle: $0^{\circ}-36^{\circ}$ (denoted by $18^{\circ}$ ), $36^{\circ}-72^{\circ}\left(\right.$ denoted by $\left.54^{\circ}\right), 72^{\circ}-108^{\circ}$ (denoted by $90^{\circ}$ ), $108^{\circ}-144^{\circ}$ (denoted by $126^{\circ}$ ) and $144^{\circ}-180^{\circ}$ (denoted by $162^{\circ}$ ), and stacked individually. All the five subazimuthal stack seismic data sets are then migrated by post-stack Kirchhoff migration method, and five azimuth migrated data sets are obtained, as shown in Fig. 6.

3. Frequency spectrum analysis of the sub-azimuth migrated data: Spectrum analysis is performed on the

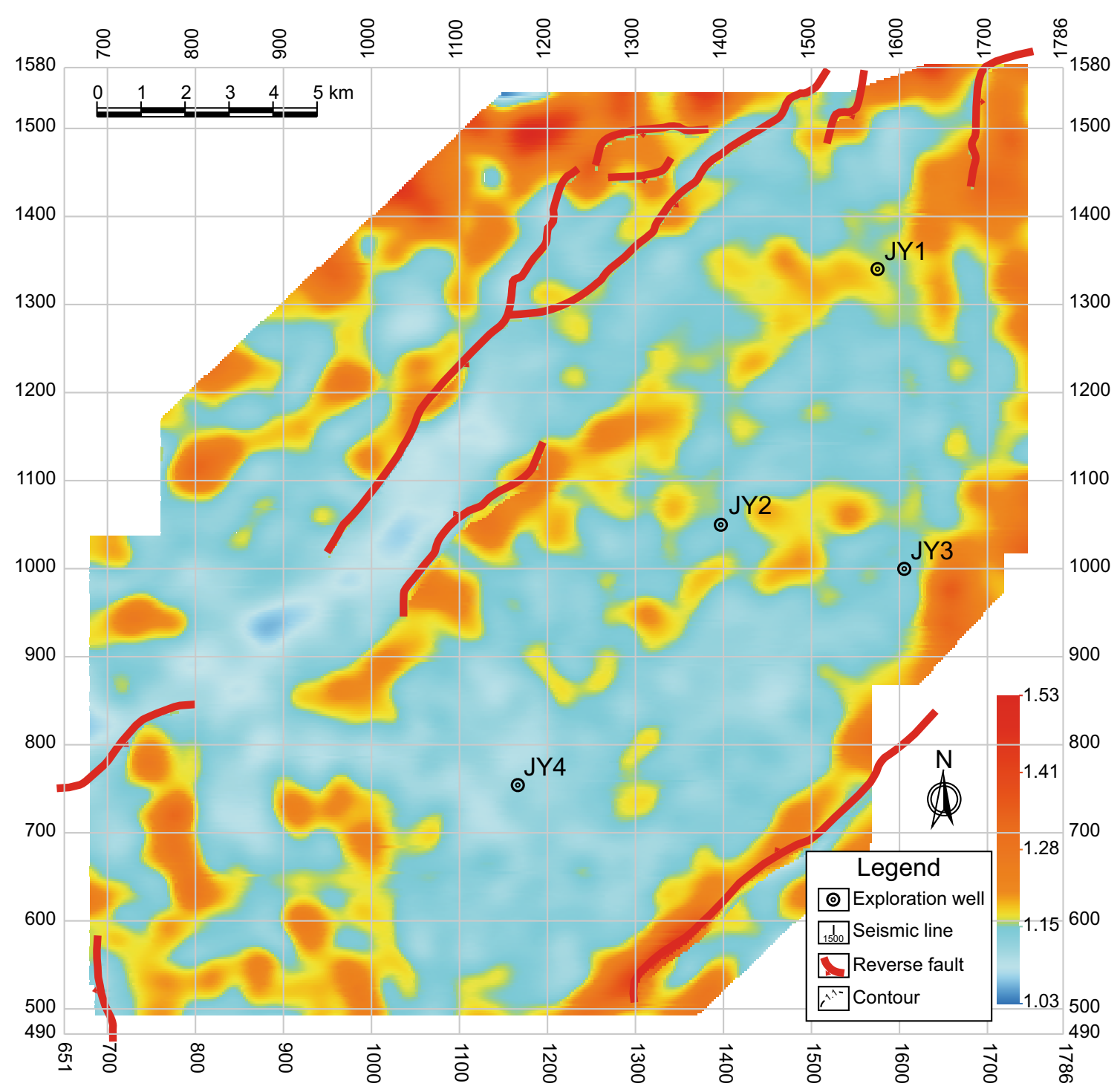

Fig. 10 Plan view of high-angle fractures of Silurian Longmaxi Formation and Ordovician Wufeng Formation in the Jiaoshiba area 
five migrated azimuth data sets with the time window from the target layer (the red layer in Fig. 6a) to the upward $50 \mathrm{~ms}$, as shown in Fig. 7. It can be seen that the frequency spectrum characteristics of all azimuthal migrated data cubes are relatively similar; however, some minor differences are noted. Such small differences are the foundation of high-angle fracture prediction from azimuthal anisotropy.

\subsection{Prediction of fractures from azimuthal anisotropy}

In order to predict the development degree and direction of the high-angle fractures, seismic attribute differences between various azimuths are used to fit an azimuthal anisotropy ellipse. According to He Zhenhua's study (He et al. 2007), the seismic dynamical properties (frequency, attenuation, etc.) are more sensitive than kinematic properties (velocity, travel time) to fractures, especially highangle fractures. In addition, the attenuation is more closely related to fractures among dynamic properties (Shen et al. 1997). In this study, image logging data are collected for attribute optimization; the optimal result leads to an attribute called the $85 \%$ attenuation frequency. The attribute indicates the frequency value $f_{m 1}$ within the effective frequency bandwidth scope where the energy attenuated to $85 \%$ of total energy, as shown in Eq. (3) and Fig. 8

$\int_{f_{1}}^{f_{m 1}} p(f) \mathrm{d} f=85 \% \int_{f_{1}}^{f_{\mathrm{h}}} p(f) \mathrm{d} f$
In this equation, $f_{\mathrm{h}}$ and $f_{1}$ are the maximum and minimum frequencies of the effective frequency bandwidth, with $p(f)$ being a function of frequency spectrum. The calculation of this property is explained here: The total energy value in the effective frequency range is calculated first, and then the frequency value corresponding to the $85 \%$ energy can be obtained. In this study, the $85 \%$ attenuation frequency attributes are calculated for each of the five azimuth data sets, and then, the azimuthal anisotropy ellipse is fitted with the five azimuth attributes. With the ratio of long and short axes as well as the direction of the long or short axis of the ellipse, the distribution of highangle fractures can be described. Comparing the imaging logging data with the through-well anisotropy intensity data sections as shown in Fig. 9a-d, the imaging logging data show that there are no fractures in the Jiaoye 4 interval and many fractures developed in intervals of wells Jiaoye 1 , Jiaoye 2 and Jiaoye 3 . Besides, the anisotropy intensity is low in the Jiaoye 4 interval and high in intervals of wells Jiaoye 1 , Jiaoye 2 and Jiaoye 3 . It can be seen that predicted high-angle fractures represented by anisotropy intensity are consistent with the fracture development measured in the image loggings, which helps to verify the accuracy of the predicted result.

The characteristics of high-angle fracture are gained by mapping the predicted anisotropy intensity data within the Silurian Longmaxi Formation and the Ordovician Wufeng Formation of the Jiaoshiba area, as shown in Fig. 10. The color scale in the picture indicates the strength of anisotropy which describes the degree of development of high-angle fractures Warm colors represent zones of development of

Table 1 Comparison between predicted fracture orientations and measured single-well fracture orientations from image logging

\begin{tabular}{|c|c|c|c|c|c|}
\hline $\begin{array}{l}\text { Well } \\
\text { name }\end{array}$ & $\begin{array}{l}\text { Predicted } \\
\text { fracture } \\
\text { orientation } \\
\text { in well }\end{array}$ & $\begin{array}{l}\text { Image logging } \\
\text { maximum } \\
\text { horizontal } \\
\text { main stress }\end{array}$ & $\begin{array}{l}\text { Well } \\
\text { name }\end{array}$ & $\begin{array}{l}\text { Predicted } \\
\text { fracture } \\
\text { orientation } \\
\text { in well }\end{array}$ & $\begin{array}{l}\text { Image logging } \\
\text { maximum } \\
\text { horizontal } \\
\text { main stress }\end{array}$ \\
\hline Jiaoye 1 & & & Jiaoy & & \\
\hline Jiaoye 2 & & & Jiaoye & & \\
\hline
\end{tabular}


high-angle fractures, and the rose diagram indicates the predominant fracture directions. It can be seen from the figure that the predicted fractures orientation is close to the maximum horizontal stress direction. Its predominant direction is east-west with a northeast-southwest subset direction. Predicted high-angle fractures mainly developed near faults rather than near box-shaped anticlines. Image logging information and predicted fracture directions in the four wells are analyzed and compared, as shown in Table 1. It can be seen from the comparison results that the singlewell prediction direction and the measured maximum stress horizontal directions are similar, which supports the idea that the prediction of fracture direction using our approach is reliable.

\section{Analysis of the relationship between fractures and shale gas accumulation}

For fractured reservoirs, fractures, especially high-angle opening fractures, not only represent transportation pathways for fluids but also provide additional hydrocarbon storage space. The degree of fracture development is therefore a very important factor for delineation of highly productive reservoirs. However, drilling and production operations indicate that shale gas is a special case. Where wells have penetrated zones of over-developed high-angle fractures (e.g., Jiaoye 3 well), the over-developed fracture is seen to result in poor preservation conditions, the shale
Table 2 Table of partial horizontal wells classified by open-flow capacity in study area

\begin{tabular}{ll}
\hline Open-flow capacity classification, $10^{4} \mathrm{~m}^{3} /$ day & Well name (Capacity, $10^{4} \mathrm{~m}^{3} /$ day) \\
\hline Less than 30 & JY3-3HF (15), JY7-2HF (15), JY1-3HF (21) \\
30-100 & JY1-2HF (51), JY11-2HF (62), JY6-2HF (82) \\
More than 100 & JY13-2HF (106), JY8-2HF (156)
\end{tabular}

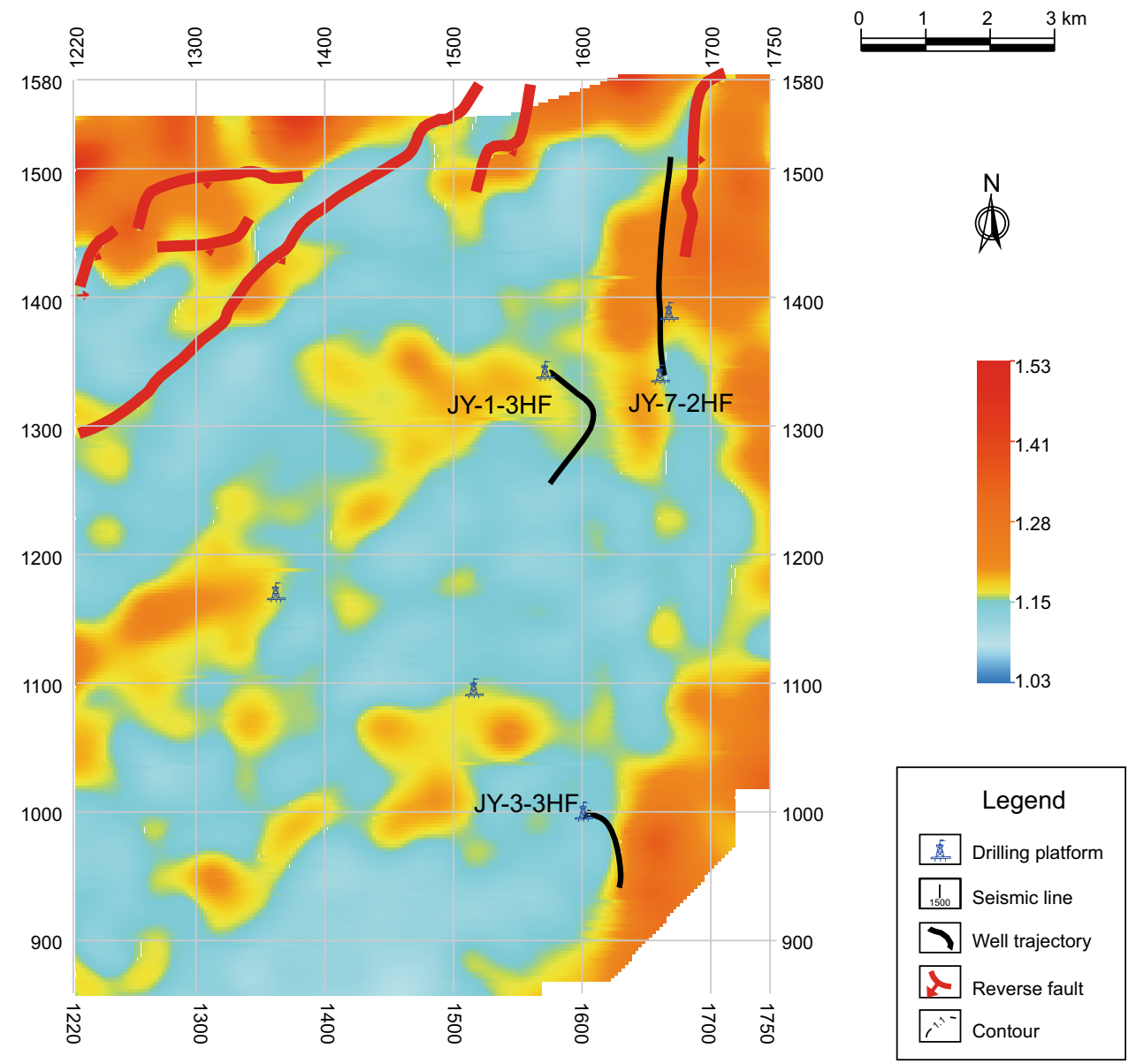

Fig. 11 Plan of predicted high-angle fracture development area showing wells with daily open-flow capacity of less than $3.0 \times 10^{5} \mathrm{~m}^{3}$ 


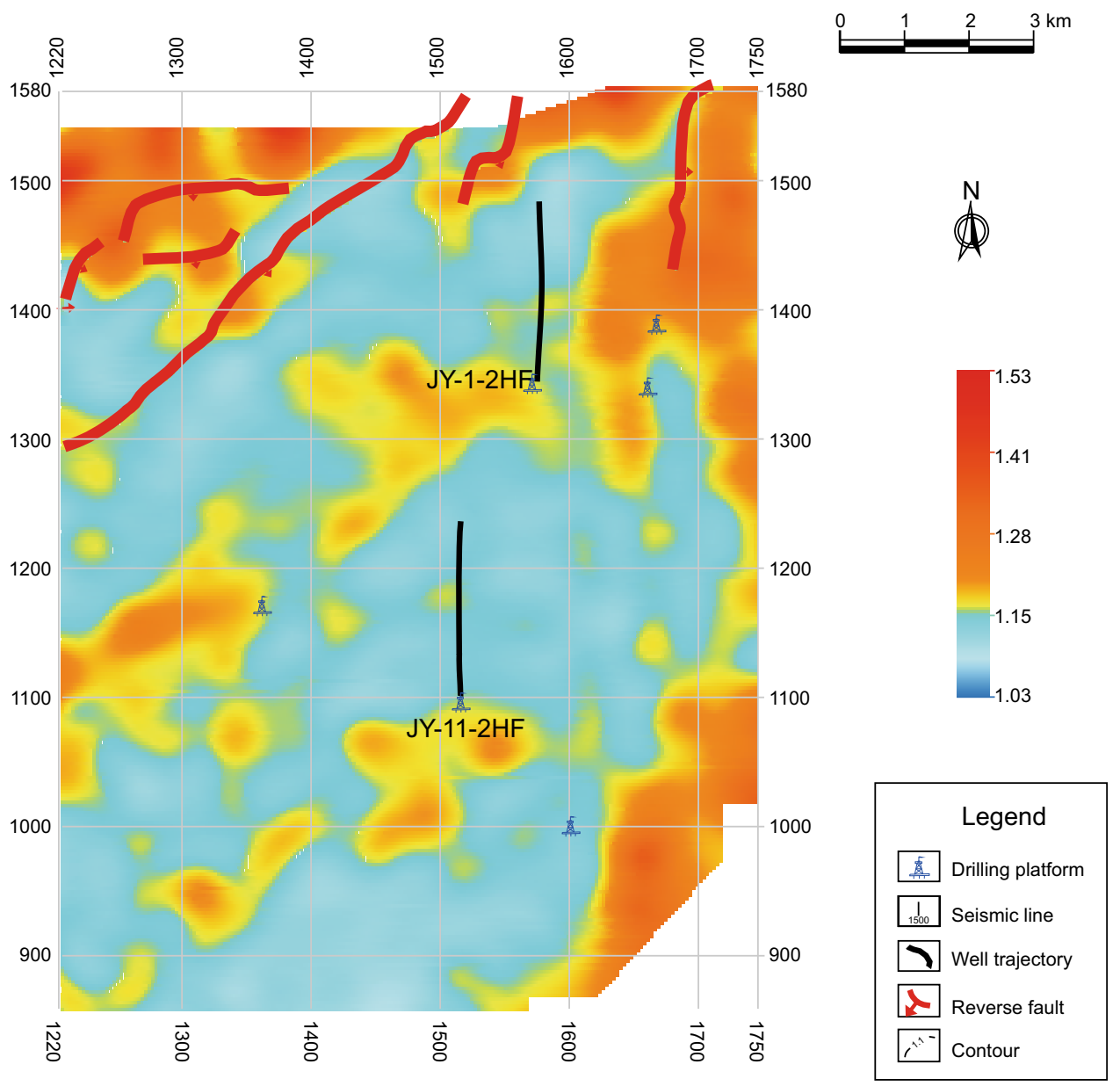

Fig. 12 Plan of predicted high-angle fracture development area showing wells with daily open-flow capacity between $3.0 \times 10^{5}$ and $1.0 \times 10^{6} \mathrm{~m}^{3}$

gas is prone to dissipating along high-angle fracture or faults, thus reducing production performance.

In order to analyze the relationship between the fractures and the well production, the prediction results are compared with the open-flow capacity of partial horizontal wells. Firstly, the wells are divided into three categories: wells with daily production less than $3.0 \times 10^{5} \mathrm{~m}^{3}$, wells with daily production between $3.0 \times 10^{5} \mathrm{~m}^{3}$ and $1.0 \times 10^{6} \mathrm{~m}^{3}$ and wells with daily production more than $1.0 \times 10^{6} \mathrm{~m}^{3}$, as shown in Table 2 (JY is short for Jiaoye, and HF means horizontal well).

Comparison of the predicted high-angle fractures with the production of the well is shown in Figs. 11, 12 and 13. The color scale represents the anisotropy strength, with warm colors representing high anisotropy strength indicating a highly developed area of high-angle fractures. Well tracks are represented by curves with arrows indicating drilling direction.

According to the comparison results, 1.15 is selected as the threshold value measuring the degree of development of high-angle fracture. Anisotropy strength values between 1 and 1.15 are considered as indicating moderate development of high-angle fractures; while anisotropy strength values greater than 1.15 are considered as indicating over-development of high-angle fractures.

By comprehensive analysis of Figs. 11, 12 and 13, the relationship between high-angle fractures and production in the case study area is determined: (1) Wells with daily production of less than $3.0 \times 10^{5} \mathrm{~m}^{3}$ are greatly influenced by the presence of high-angle fractures, and there are many horizontal sections through the zones of highly developed high-angle fractures in the low-yield wells; (2) in the wells with daily production between $3.0 \times 10^{5} \mathrm{~m}^{3}$ and $1.0 \times 10^{6} \mathrm{~m}^{3}$, portions of horizontal well section pass through zones of highly developed high-angle fractures; (3) in the wells with daily production more than $1.0 \times 10^{6} \mathrm{~m}^{3}$, such as the well Jiaoye 8 - $2 \mathrm{HF}$ in the northeastern of the work area, none of sections of the well encounters overdeveloped zones of high-angle fracture; and the Jiaoye 13-2 well only encounters a few over-developed zones of high-angle fracture at the end of the horizontal sections.

Judging by the contrast results, when the predicted anisotropy strength value is greater than 1.15 , representing 


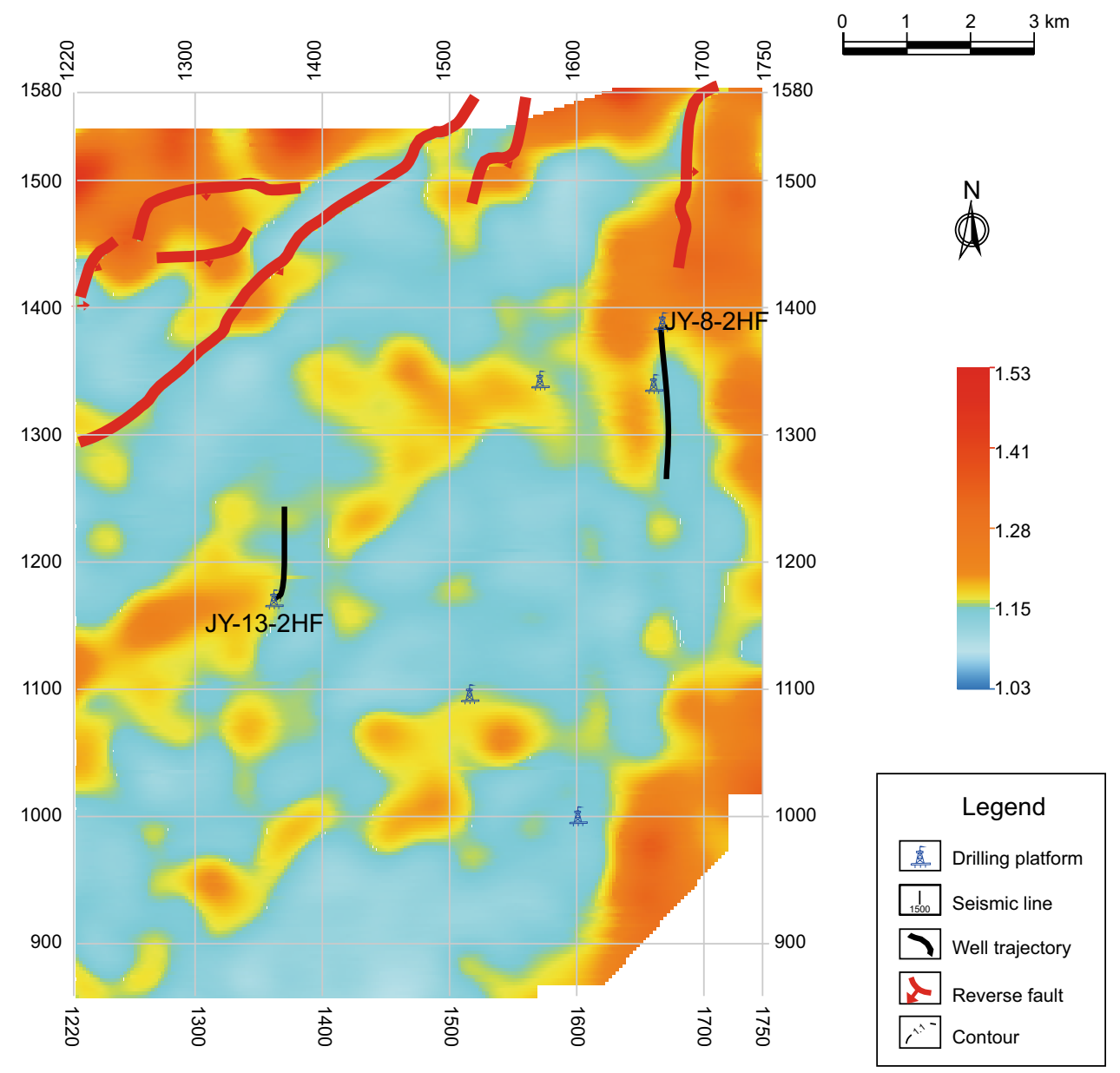

Fig. 13 Plan of predicted high-angle fracture development area showing wells with daily open-flow capacity more than $1.0 \times 10^{6} \mathrm{~m}^{3}$

an over-development of high-angle fractures, it would result in gas dispersion and is detrimental to gas enrichment and high production. When the predicted anisotropy strength values are between 1 and 1.15 , it would be favorable for gas enrichment and high production. Therefore, during the design of shale gas horizontal well trajectories, it is necessary to avoid over-developed zones of high-angle fractures with complicated structures and faults, and to search for moderately developed zones of high-angle fractures, so as to enhance the economic benefits of shale gas exploration and development.

\section{Conclusions}

Based on logging data, well production data, seismic data and laboratory data, an in-depth study of the shale gas reservoirs in the Longmaxi Formation of the Jiaoshiba area has been carried out using various geophysical methods and approaches. This study analyzes the relationship between the degree of shale fracture development and shale gas accumulation and high productivity. The following two major conclusions have been drawn:

1. Rock core tracer diffusion tests indicate that fractures are the principle transportation pathways of shale gas, and high-angle fracture zones promote gas enrichment.

2. Fracture prediction results based on azimuthal anisotropy show that the relationship between the degree of development of high-angle fractures and the degree of enrichment of shale gas can be quantified by azimuthal anisotropy strength. When azimuthal anisotropic strength values are greater than 1.15 , it will result in the destruction of the shale reservoir preservation conditions. When azimuthal anisotropic strength values are between 1 and 1.15 , it is beneficial to the gas enrichment and high productivity.

In addition, the bedding-parallel fracture in the shale formation is mostly small and almost impossible to predict with seismic data. But this type of fracture is also significant to shale gas enrichment. How to use geophysical techniques to solve these prediction problems will be a long-term research direction of petroleum geophysics. 
Acknowledgements The authors would like to thank the editors and reviewers for their valuable comments. This work is supported by the National Key Basic Research Program of China (973 Program, No. 2014CB239104), National Science and Technology Major Project (No. 2017ZX05049002-005), Sinopec Basic Prospect Project (No. G5800-16-ZS-KJB043) and NSFC-Sinopec Joint Key Project (No. U1663207).

Open Access This article is distributed under the terms of the Creative Commons Attribution 4.0 International License (http://creative commons.org/licenses/by/4.0/), which permits unrestricted use, distribution, and reproduction in any medium, provided you give appropriate credit to the original author(s) and the source, provide a link to the Creative Commons license, and indicate if changes were made.

\section{References}

Chen HZ, Yin XY, Gao CG, et al. AVAZ inversion for fluid factor based on fracture anisotropy rock physics theory. Chin J Geophys. 2014a;57(3):968-78. https://doi.org/10.6038/ cjg20140326 (in Chinese).

Chen HZ, Yin XY, Gao JH, et al. Seismic inversion for underground fractures detection based on effective anisotropy and fluid substitution. Sci China Earth Sci. 2015;58(5):805-14. https://doi. org/10.1007/s11430-014-5022-1.

Chen HZ, Yin XY, Zhang JQ, et al. Seismic inversion for fracture rock physics parameters using azimuthally anisotropic elastic impedance. Chin J Geophys. 2014b;57(10):3431-41. https://doi. org/10.6038/cjg20141029.

Deng JX, Wang H, Zhou H, et al. Microtexture, seismic rock physical properties and modeling of Longmaxi Formation shale. Chin J Geophys. 2015;58(6):2123-36. https://doi.org/10.6038/ cjg20150626 (in Chinese).

Fan GZ, Mu YG. Variations of P-wave velocity in fractured anisotropic media and their impacts to stacking of CMP gathers. Geophys Prospect Pet. 2002;41(1):49-55 (in Chinese).

Gale JFW, Laubach SE, Olson JE, et al. Natural fractures in shale: a review and new observations. AAPG Bull. 2014;98(11):2165-216. https://doi.org/10.1306/08121413151.

Guo TL, Liu RB. Implications from marine shale gas exploration breakthrough in complicated structural area at high thermal stage: taking Longmaxi Formation in well JYl as an example. Nat Gas Geosci. 2013;24(4):643-51 (in Chinese).

Guo TL, Zhang HR. Formation and enrichment mode of Jiaoshiba shale gas field, Sichuan Basin. Pet Explor Dev. 2014;41(1):28-36. https://doi.org/10.1016/S18763804(14)60003-3 (in Chinese).

Guo TL. Discovery and characteristics of the Fuling shale gas field and its enlightenment and thinking. Earth Sci Front. 2016a;23(1):29-43. https://doi.org/10.13745/j.esf.2016.01.003 (in Chinese).

Guo TL. Key geological issues and main controls on accumulation and enrichment of Chinese shale gas. Pet Explor Dev. 2016b;43(3):317-26. https://doi.org/10.1016/S18763804(16)30042-8 (in Chinese).

Guo TL. The Fuling Shale Gas Field-a highly productive Silurian gas shale with high thermal maturity and complex evolution history, southeastern Sichuan Basin, China. Interpretation. 2015;3(2):25-34. https://doi.org/10.1190/INT-2014-0148.1.

Guo XS, Hu DF, Li YP, et al. Geological factors controlling shale gas enrichment and high production in Fuling shale gas field. Pet Explor Dev. 2017;44(4):481-91. https://doi.org/10.11698/PED. 2017.04.01 (in Chinese).
Hao SL, Zhao Q. The effect of fractured medium on $\mathrm{P}$ wave azimuthal anisotropy: a physical model study. Prog Explor Geophys. 2004;27(3):189-94 (in Chinese).

He ZH, Huang DJ, Wen XT. Geophysical predictive theory and technique on fractured reservoir. Chengdu: Sichuan Publishing House of Science and Technology; 2007. p. 103-6 (in Chinese).

Jia CZ. Breakthrough and significance of unconventional oil and gas to classical petroleum geological theory. Pet Explor Dev. 2017;44(1):1-11. https://doi.org/10.11698/PED.2017.01.01 (in Chinese).

Jiang S, Zhang JC, Jiang ZQ, et al. Geology, resource potentials, and properties of emerging and potential China shale gas and shale oil plays. Interpretation. 2015;3(2):1-13. https://doi.org/10.1190/ INT-2014-0142.1

Jin ZJ, Hu ZQ, Gao B, et al. Controlling factors on the enrichment and high productivity of shale gas in the Wufeng-Longmaxi Formations, southeastern Sichuan Basin. Earth Sci Front. 2016;23(1):1-10. https://doi.org/10.13745/j.esf.2016.01.001 (in Chinese).

Kong LY, Wang YB, Yang HZ. Fracture parameter analysis in fracture-induced HTI double-porosity medium. Chin J Geophys. 2012;55(1):189-96. https://doi.org/10.6038/j.issn.0001-5733. 2012.01.018 (in Chinese).

Liang C, Jiang ZX, Yang YT, et al. Characteristics of shale lithofacies and reservoir space of the Wufeng-Longmaxi Formation, Sichuan Basin. Pet Explor Dev. 2012;39(6):691-8 (in Chinese).

Mallick S, Craft K, Meister L, et al. Determination of the principle direction of azimuthal anisotropy from $\mathrm{P}$-wave seismic data. Geophysics. 1998;63:692-706. https://doi.org/10.1190/1. 1444369

Ruger A. P-wave reflection coefficients for transversely isotropic models with vertical and horizontal axis of symmetry. Geophysics. 1997a;62(3):713-22. https://doi.org/10.1190/1. 1444181.

Ruger A. Using AVO for fracture detection: analytic basis and practical solutions. Lead Edge. 1997b;16(10):1429-34. https:// doi.org/10.1190/1.1437466.

Shen F, Zhu X, Toksoz N. Anisotropy of aligned fractures and P-wave azimuthal AVO response. SEG Annual Meeting; 1997. p. 2001-4. https://doi.org/10.1190/1.1885842.

Sun W, He ZL, Li YF, et al. An improved method of fracture prediction based on P-wave anisotropy. Oil Geophys Prospect. 2014a;49(6):1170-8 (in Chinese).

Sun W, Li YF, Fu JW, et al. Review of fracture identification with well logs and seismic data. Prog Geophys. 2014b;29(3):1231-42. https://doi.org/10.6038/pg20140332 (in Chinese).

Sun W, Li YF, He WW, et al. Using P-wave azimuthal anisotropy to predict fractures in carbonate reservoirs of the ZY block. Oil Gas Geol. 2013a;34(1):137-44 (in Chinese).

Sun WJ, Fu LY, Guan XZ, et al. A study on anisotropy of shale using seismic forward modelling in shale gas exploration. Chin J Geophys. 2013b;56(3):961-70. https://doi.org/10.6038/ cjg2013032 (in Chinese).

Tenger B, Shen BJ, Yu LJ, et al. Mechanisms of shale gas generation and accumulation in the Ordovician Wufeng-Longmaxi Formation, Sichuan Basin, SW China. Pet Explor Dev. 2017;44(1):69-78. https://doi.org/10.11698/PED.2017.01.08 (in Chinese).

U.S. Energy Information Administration (EIA). Technically recoverable shale oil and shale gas resources: an assessment of 137 shale formations in 41 countries outside the United States[R/OL]. http://www.eia.gov/analysis/studies/worldshalegas/pdf/over view.pdf. Accessed 13 June 2013.

Wang HJ, Ma F, Tong XG, et al. Assessment of global unconventional oil and gas resources. Pet Explor Dev. 2016;43(6):850-62. https://doi.org/10.11698/PED.2016.06.02 (in Chinese). 
Wang SQ. Status, problems and prospects of exploitation of shale gas resources. Nat Gas Ind. 2017;37(6):115-30. https://doi.org/10. 1016/j.ngib.2017.12.004 (in Chinese).

$\mathrm{Wu} \mathrm{TH}$, Zhang DX. Impact of adsorption on gas transport in nanopores. Sci Rep. 2016. https://doi.org/10.1038/srep23629.

Yang $\mathrm{R}, \mathrm{He} \mathrm{S}, \mathrm{Hu} \mathrm{QH}$, et al. Applying SANS technique to characterize nano-scale pore structure of Longmaxi shale, Sichuan Basin (China). Fuel. 2017a;197:91-9. https://doi.org/ 10.1016/j.fuel.2017.02.005.

Yang R, He S, Hu QH, et al. Geochemical characteristics and origin of natural gas from Wufeng-Longmaxi shale of Fuling gas field, Sichuan Basin (China). Int J Coal Geol. 2017b;171:1-11. https:// doi.org/10.1016/j.coal.2016.12.003.

Yin ZH, Li XY, Wei JX, et al. A physical modelling study on the 3D P-wave azimuthal anisotropy in HTI media. Chin J Geophys.
2012;55(11):3805-12. https://doi.org/10.6038/j.issn.0001-5733. 2012.11.027 (in Chinese).

Zeng LB, Xiao SR. Fractures in the mudstone of tight reservoirs. Petroleum Geology \& Experiment. 1999;21(3):266-269. (in Chinese).

Zhang JC, Xu B, Nie HK, et al. Exploration potential of shale gas resources in China. Nat Gas Ind. 2008;28(6):136-40 (in Chinese).

Zhang K, Guo YX, Zhang B, et al. Seismic azimuthal anisotropy analysis after hydraulic fracturing. Interpretation. 2013;1(2):27-36. https://doi.org/10.1190/INT-2013-0013.1.

Zhou Y, Yuan YS, Qiu DF. A discussion on formation and evolutionary pattern of shale structural fracture: a case study of shale in western Sichuan Basin. Oil Gas Geol. 2015;36(5):828-34. https://doi.org/10.11743/ogg20150515 (in Chinese). 